\title{
Second-best trade policies in Cournot oligopoly
}

\author{
Luis C. Corchón ${ }^{1}$, Miguel González-Maestre ${ }^{2}$ \\ 1 Departamento de Economía, Universidad Carlos III, c/Madrid 126, 28903 Getafe, Madrid, Spain \\ 2 Universidad de Murcia, Facultad de Economía y Empresa, Departamento de Fundamentos del \\ Análysis Económico, Campus de Espinardo, 301000 Murcia, Spain (e-mail: mmaestre@um es)
}

\begin{abstract}
In this paper we study the optimal import policy in an oligopolistic market with a given number of quantity-setting firms. In the absence of fixed costs, we show that if the policy instrument is an import quota, the optimal policy is either free trade or autarky, while if the instrument is a tariff the optimal policy is neither free trade nor autarky. In the case of fixed costs, we show that contrary to the traditional protectionist argument, a restrictive import policy might increase domestic welfare by increasing domestic consumers' surplus, instead of increasing domestic profits.
\end{abstract}

JEL classification: L13, F12, F13

Key words: Import policy, oligopoly, quotas, tariffs

\section{Introduction}

There is a sizable literature studying the strategic import policy, i.e. the effects of economic policy in a oligopolistic market subject to foreign competition [see, for instance, Dixit (1984); Helpman (1984); Buffie and Spiller (1986); Eaton and Grossman (1986); Laussel et al. (1988); Markusen and Venables (1988); Das and Donnenfeld (1989); Krugman, 1989; Ono (1990); Krishna and Thursby (1991); Barros and Cabral (1992)]. Such effects look different from those under perfect competition, as often occurs in a second-best framework.

We are grateful to seminar audiences in Alicante, Toulouse and Viena and to J Friedman, C Herrero, I Jiménez-Raneda, F Marhuenda, A Mas-Colell, I Ortuño-Ortín, J A Silva, I Steedman, two anonimous referees and an associate editor for helpful comments We are solely responsible for any remaining error We acknowledge support from DGICYT under project PB 93 - 0940 and the hospitality from Royal Complutense College

Correspondence to: M González-Maestre 
Trade policy under positive fixed costs has been studied by Dixit and Kyle (1985), Motta (1992) and Rowthorn (1992). The closest paper to ours' is that by Horstman and Markusen (1992). They show (in a model somewhat different from ours') that small changes in tariffs may yield large effects on welfare. However, they do not characterize the optimal trade policy.

In this paper, we focus our attention on the second-best import policy, i.e. the optimal import policy with the restriction that the domestic market is oligopolistic. In order to make our point, we take the simplest model, namely Cournot equilibrium with a given number of firms and an unique foreign firm. The task of this paper is to characterize the shape of the second-best trade policy under two alternative policy instruments: quotas and tariffs.

We first analyze the no fixed cost case. We show the following:

1) When quotas are the only policy instrument, second-best is neither a small quota nor a quota for which domestic production is almost zero (see Proposition 1(i)). The second best is either free trade or complete protection (see Proposition 1(ii)). If domestic firms are efficient (resp. inefficient) relative to the foreign firm, complete protection (resp. free trade) is second-best. If domestic and foreign firms are identical, we find conditions under which complete protection is second-best (see Proposition 1(iii)).

2) When the only policy instrument is a tariff on output we show that domestic welfare is increasing in the tariff when domestic output is zero, and decreasing when the foreign firm is inactive (see Proposition 2(i)). We show that the secondbest tariff exists, is interior, and, under an additional assumption, unique. We also find a sufficient condition for the optimal tariff to be positive (see Proposition 2(ii)). Similar results can be obtained if the tariff is proportional to sales.

We remark that in contrast with the previous literature, the above results are not restricted to linear demand functions, and we identify general conditions on the demand function ensuring that the second-best policy exists, is unique and is located in the interior (tariffs) or in the corner (quotas). In fact, our analysis shows that existence and uniqueness are nontrivial issues.

Next, we assume that there is a unique domestic firm with a technology characterized by a fixed cost and a constant marginal cost. Consequently, the reaction of the domestic firm to certain trade policies is discontinuous. ${ }^{1}$ We show the following:

3) The second-best quota may be complete protection, free trade or a level of imports in which domestic firm's profits are zero but domestic output is positive (see Proposition 3). We call the latter situation Ramsey pricing.

4) If the available instrument is a tariff, the solution may be interior or corner. The latter may be complete protection or Ramsey pricing either for the domestic or for the foreign firm (see Proposition 4).

\footnotetext{
${ }^{1}$ Positive fixed costs are usually associated to free entry (see Krugman 1979; Helpman 1981; Venables 1985; Horstman and Markusen 1986; Markusen and Venables 1988) However, none of these papers focuses on the impact of the discontinuous behaviour of the domestic firm on the design of economic policy
} 
Summing up, under positive fixed costs, Ramsey pricing or protectionist tariffs may be second-best. Moreover, the level of the optimal instrument may be related to the underlaying parameters in a non intuitive way. Of course, these conclusions are tentative until more general models had been analyzed, but this is outside the scope of this paper.

The rest of the paper goes as follows. Section 2 presents the model. Sections 3 and 4 study respectively the cases of zero and positive fixed cost. Section 5 offers our final comments. All proofs are gathered in an Appendix.

\section{The model}

There is a unique consumer with utility function $u(x)-p x$, where $x$ is the consumption of the homogeneous good and $p$ is market price. We assume that $u(0)=0, u^{\prime}(x)>0$ and $u^{\prime \prime}(x)<0 \forall x$. There are $n$ domestic firms with cost functions denoted by $c_{i}\left(x_{i}\right), i=1, \ldots, n$ where $x_{i}$ is the output of firm $i$. Let $x_{d}=\sum_{i=1}^{n} x_{i}$ be domestic output and $\pi_{d}=p . x_{d}-\sum_{i=1}^{n} c_{i}\left(x_{i}\right)$ be aggregate domestic profits. There is a unique foreign firm with a cost function denoted by $c_{f}\left(x_{f}\right)$ where $x_{f}$ stands for imports. Thus $x=x_{d}+x_{f}$. Cost functions of both domestic and foreign firms are increasing and twice continuously differentiable for strictly positive outputs.

The instruments in the hands of the government are tariffs and quotas. We assume that the decision on them is prior to the decision of firms on outputs, i.e., the government acts as a Stackelberg leader [for different assumptions on the timing of the game see González-Maestre (1993) and Collie (1993)].

Domestic welfare, denoted by $S$, is the sum of producers' and consumer's surpluses plus the rents captured by the government via tariffs, denoted by $R$, i.e. $S=u(x)-p x+\pi_{d}+R$. Assuming that the consumer is perfectly competitive we have that $p=u^{\prime}$ and therefore

$$
S=u(x)-u^{\prime}(x) x_{f}-\sum_{i=1}^{n} c_{i}\left(x_{i}\right)+R .
$$

We assume that firms are profit maximizers taking as given the outputs of other firms and the policy instrument. Assuming interiority for domestic firms, first order conditions of a Cournot equilibrium, relative to a quota $\mathrm{Q}$ and a tariff t. $x_{f}$ read:

$$
\begin{gathered}
p\left(x_{f}+x_{d}\right)+x_{i} p^{\prime}\left(x_{f}+x_{d}\right)-c_{i}^{\prime}\left(x_{i}\right)=0 \quad i=1, \ldots, n, \\
p\left(x_{f}+x_{d}\right)+x_{f} p^{\prime}\left(x_{f}+x_{d}\right)-c_{f}^{\prime}\left(x_{f}\right)-t \geq 0, \quad Q \geq x_{f} .
\end{gathered}
$$

We will assume that for sufficiently large outputs costs are not recovered. This allows us to restrict attention to a compact interval in which any possible equilibrium must lie. All the subsequent assumptions must be understood as referring to outputs in this interval. We now assume 


\section{Assumption 1.}

a) $\forall x, x_{j}, p^{\prime \prime} x_{j}+p^{\prime}<0, \quad j=1, \ldots, n, f$

b) $p^{\prime}-c_{j}^{\prime \prime}<0, \quad j=1, \ldots, n, f$.

This assumption (A.1 in the sequel) is standard in the Cournot model [see e.g. Friedman (1982) Assumption 3, p. 496, and Brander and Spencer (1984)]. The interpretation of A.1 is that marginal revenue declines faster than price and price declines faster than marginal costs [see Helpman and Krugman (1989) p. 55].

A.1 implies that the profit function is strictly concave with respect to the own output. This implies that (2) and $\left(2^{\prime}\right)$ are sufficient conditions of profit maximization and that the Cournot equilibrium exists and is unique [see Friedman (1982), Theorem 1, p. 496 and Collie (1992)].

Let $\bar{x}_{j}, j=1, \ldots, n, f$, be the output of firm $j$ in the Cournot equilibrium with no quotas. Another implication of A.1 is that firm $f$ produces at least the quota if the quota is smaller than equilibrium output of firm $f$ with no quotas. This follows from the fact that $x_{f}$ is decreasing on domestic output. Thus, the quota will also be denoted by $x_{f}$ when $Q \leq \bar{x}_{f}$.

\section{The case of no fixed costs}

In this section we characterize the second-best policy when there are no fixed costs. We first consider that no tariff is available. Let $S\left(x_{f}\right)$ be domestic welfare in a Cournot equilibrium relative to the quota. Let $\beta=\beta(x) \equiv p^{\prime \prime}(x) x / p^{\prime}(x)$. $\beta$ can be interpreted as the degree of concavity of the inverse demand function. Then, we have our first result:

Proposition 1. Under A.1, the following properties hold:

i) Domestic welfare is decreasing in $x_{f}$ for small level of imports and increasing in $x_{f}$ for small domestic output. Therefore, the second-best quota is not very small or such that the domestic industry produces almost zero.

ii) If domestic firms are identical, the technology displays constant returns to scale and $\beta(x)$ is non increasing on $x, S\left(x_{f}\right)$ is quasi-convex on $x_{f}$ and the second-best is either free trade or autarky.

iii) If all firms (including the foreign) are identical, the technology displays constant returns to scale, and either $n=1$ and the inverse demand function is concave or $n>1$, then the second-best policy is autarky. ${ }^{2}$

That a small level of imports reduces welfare has been proved in the case of $n=1$ by Eldor and Levin (1990). Proposition 1(i) shows that this property

\footnotetext{
${ }^{2}$ Proposition 1 part iii) is different in the case of $h$ identical foreign firms with constant returns to scale In this case, easy calculations show that if $h>n$ and $\beta<2+1 / n, \frac{d S}{d x_{f}}\left(\bar{x}_{f}\right)>0$ If $h=n, \frac{d S}{d x_{f}}\left(\bar{x}_{f}\right)<0$ iff $p()$ is concave And if $h<n$ and A 1 holds, $\frac{d S}{d x_{f}}\left(\bar{x}_{f}\right)<0$ Thus, the number of foreign firms is a critical variable in the determination of the optimal quota The more foreign firms are prepared to enter the domestic market, the less likely is that autarky is second-best since with many foreign firms aggregate output is large, and if $S($ ) is quasi-convex, domestic welfare is maximized with free trade A similar case arises when only foreign firms have market power (see, e g Helpman and Krugman 1989, p 63)
} 
holds for any $n$. In addition, it shows that a quota for which the domestic output is almost zero can not be optimal. The intuition behind Proposition 1(i) is that the effect of an increase in quotas on social welfare can be decomposed in two elements. On the one hand a positive effect, which comes from an increase in aggregate output caused by the increase in quotas. On the other hand, production of domestic firms falls, which is socially harmful since price is higher than marginal cost. Thus if $x_{f}$ is zero the first effect vanishes so that only the second effect remains (see Ono 1990) and if domestic output is zero only the first effect remains.

An implication of Proposition 1(i) is that there exists a quota for which the derivative of $S\left(x_{f}\right)$ equals to zero - so the first order condition of welfare maximization is fulfilled - but total welfare is minimized. Therefore, the optimal quota can not be found by calculus. This suggests that the second-best trade policy is either free trade or complete protection. This intuition is confirmed by Proposition 1(ii), which identifies sufficient conditions on the demand function ensuring this property. This result has been obtained by Eldor and Levin (1990) and by Laussel et al. (1988) in the case of linear demand and one domestic firm (the last paper allows for some product differentiation which can be easily introduced in our model). Notice that A.1 and our assumption on $\beta$ allow for inverse demand functions of the form $p=a-x^{\alpha}$, with $\alpha>0$ or $p=e^{-b x}$ with $b>0$ (in the last case, provided that $x$ has an upper bound small enough).

It can be shown that, under A. $1, \bar{x}_{f}$ is decreasing with the (constant) marginal cost of the foreign firm (see Collie 1992). Thus, an interpretation of Proposition 1(ii) is that if domestic firms are relatively efficient, the output of the foreign firm in a Cournot equilibrium with no quotas is small and it is likely that it is located on the decreasing part of $S($ ). Thus, autarky is the best policy. Conversely, if domestic firms are relatively inefficient it is likely that the optimal policy is free trade. Therefore, it is likely that second-best policy agrees with the commandment "Do not protect the inefficient" (or "do not allow foreign mediocrities to enter").

Proposition 1(ii) says that second-best policy is either autarky or free trade. If $S$ ( ) is decreasing at free trade, the quasi-convexity of $S$ ( ) implies that domestic welfare is maximized in autarky. Proposition 1(iii) provides a sufficient condition for $S$ ( ) to be decreasing at free trade.

Next we consider the case of a linear tariff on foreign output. The case where the tariff depends on sales of the foreign firm (i.e. ad valorem tariff) can be studied by similar methods.

It can be shown (see Collie 1992) that under A.1 there is a unique Cournot equilibrium relative to $t$, i.e. a unique vector of outputs satisfying equations (2) and $\left(2^{\prime}\right)$. Let $S(t), x_{i}(t), x_{f}(t)$ and $x(t)$, respectively, be domestic welfare, output of domestic firm $i$, output of the foreign firm, and aggregate output, evaluated in a Cournot equilibrium for a given tariff $t$.

We now concentrate on the characterization of the optimal tariff. In the following, we will assume constant marginal costs - denoted by $c$ - and identical firms (including the foreign).

Now, let us define $\underline{t}$ and $\bar{t}$, respectively, by the following conditions: 


$$
p(x(\underline{t}))-c=0 . \quad p(x(\bar{t}))-c-\bar{t}=0 .
$$

In words, facing a tariff $\bar{t}$ the foreign firm chooses zero output, while $\underline{t}$ is the tariff for which domestic firms will choose zero output. (Note that $\underline{t}$ is a subsidy, since $\underline{t}$ is negative). We have the following auxiliary result:

Lemma 1. Let us assume A.1 and that $p(x)$ tends to 0 when $x$ tends to infinity, then

(i) $\bar{t}$ and $\underline{t}$ exist, and

(ii) $x_{i}(t)$ is increasing, $x_{f}(t)$ is decreasing and $x(t)$ decreasing.

Moreover $\bar{t}$ and $\underline{t}$ are unique.

Let $t^{*}$ be the second-best tariff, that is, the tariff which maximizes $S(t)$. We have the following result.

Proposition 2. Under A.1, constant returns to scale and identical firms (including the foreign), the following properties hold:

i) If $n \geq 1$, the domestic welfare is strictly decreasing at $t=\bar{t}$ and strictly increasing at $t=\underline{t}$.

ii) $t^{*}$ exists, is positive and satisfies $\underline{t}<t^{*}<\bar{t}$ if $n \geq 1$. If $\beta()$ is non decreasing in $x, S(t)$ is strictly quasiconcave and $t^{*}$ is unique.

Proposition 2(i) implies that a prohibitive tariff (that is, a tariff which implies autarky) is never optimal. It also implies that it is not optimal to set a tariff yielding a very small (but positive) level of domestic output. This result contrasts with the one obtained in Proposition 1 for quotas since what is shown here is that the second-best tariff is interior.

Proposition 2(i) has been proved in the case of $n=0$ by Brander and Spencer (1985). However they did not study the second order condition, so that they did not prove neither existence nor uniqueness. In the case $n \geq 1$, Collie (1991) argued that $t^{*}$ is positive if $p(x)$ is "sufficiently concave". However, although he calculates the second order condition for a local maximum, he did not provide sufficient conditions ensuring existence, uniqueness and interiority of second-best tariffs. In the case of cost differences between domestic and foreign firms, Dixit (1988) has analyzed the prohibitive tariff, when it is second-best. ${ }^{3}$

\section{The case of positive fixed costs}

In this section we analyze the case of positive fixed costs. In this case, the behavior of firms becomes discontinuous at certain points and this complicates the analysis of the optimal trade policy. In order to keep the analysis tractable, we will simplify further the model by assuming a unique domestic firm with

\footnotetext{
${ }^{3}$ Notice that $t^{*}$ is not always decreasing on the degree of competition Let $h$ be the number of foreign firms If $u(x)=a x-x^{2} / 2, t^{*}=(a-c)(2 n+1) /\left(h+2(n+1)^{2}\right)$ Thus, for $h$ large $d t^{*} / d n>0$ (see Helpman and Krugman 1989, p 186)
} 
constant marginal cost (this is Assumption 2 below). Even in this case, we will see that the main conclusions obtained in this section are considerably more complex than those obtained in Sect. 3. These conclusions must be understood as a warning that the results obtained in Sect. 3 do not generalize to the case of positive fixed costs. More general assumptions than A.2 will produce even more ambiguous results.

Assumption 2. There is a unique domestic firm whose cost function is given by $c\left(x_{i}\right)=K+c x_{i}$ if $x_{i}>0$ and $c(0)=0$.

Let $x_{i}\left(x_{f}\right)$ be the profit maximizing output of the domestic firm as a function of imports. Under A.1 a) this correspondence is single valued as long as domestic profits are positive. If domestic profits are zero, there are two outputs -one positive, the other zero- maximizing profits. In this case we assume that the domestic firm produces a positive output. Thus $x_{i}\left(x_{f}\right)$ is single valued. Let $x\left(x_{f}\right)=x_{i}\left(x_{f}\right)+x_{f}$. Define

$$
\hat{x}_{f}=\left\{x_{f} \mid p\left(x\left(x_{f}\right)\right) x_{i}\left(x_{f}\right)-c\left(x_{i}\left(x_{f}\right)\right)=0, \quad x_{i}\left(x_{f}\right)>0\right\} .
$$

In words, $\hat{x}_{f}$ is the output of the foreign firm for which the maximum profits of the domestic firms are zero, i.e. the output corresponding to limit pricing of the foreign firm. We now show the following

Lemma 2. $\hat{x}_{f}$ exists and if $x_{i}\left(\hat{x}_{f}\right)>0$, it is unique.

Proof. If $\forall y, 0 \geq p(y) y-c(y)$, then $\hat{x}_{f}=0$. If $\exists y$ such that $p(y) y-c(y) \geq 0$ the median value theorem and our boundness assumptions imply the existence of $\hat{x}_{f}$. Let us prove uniqueness. Suppose there are two different $\hat{x}_{f}$, denoted by $\hat{x}_{f}$ and $\hat{x}_{f^{\prime}}$ and without loss of generality assume that $\hat{x}_{f}<\hat{x}_{f^{\prime}}$. Then we have

$$
0=p\left(x\left(\hat{x}_{f}\right)\right) x_{i}\left(\hat{x}_{f}\right)-c x_{i}\left(\hat{x}_{f}\right) \geq p\left(x_{i}\left(\hat{x}_{f^{\prime}}\right)+\hat{x}_{f}\right) x_{i}\left(\hat{x}_{f^{\prime}}\right)-c\left(x_{i}\left(\hat{x}_{f^{\prime}}\right)\right)
$$

and

$$
p\left(x\left(\hat{x}_{f^{\prime}}\right)\right) x_{I}\left(\hat{x}_{f^{\prime}}\right)-c x_{i}\left(\hat{x}_{f^{\prime}}\right)=0 .
$$

But since $p()$ is decreasing

$$
p\left(x_{i}\left(\hat{x}_{f^{\prime}}\right)+\hat{x}_{f}\right) x_{i}\left(\hat{x}_{f^{\prime}}\right)-c\left(x_{i}\left(\hat{x}_{f^{\prime}}\right)\right)>p\left(x\left(\hat{x}_{f^{\prime}}\right)\right) x_{i}\left(\hat{x}_{f^{\prime}}\right)-c x_{i}\left(\hat{x}_{f^{\prime}}\right)=0
$$

which contradicts the first equality.

Lemma 2 simplifies the task of finding the second-best quota since it shows that the function $S$ (.) can be decomposed in two parts. If $0 \leq x_{f}<\hat{x}_{f}, S($.) looks as in the no fixed cost case. When $\hat{x}_{f}=x_{f}, S($.$) is multivalued but (according with$ our assumption on $\left.x_{i}().\right)$ we take the maximum value. Since in this allocation the domestic firm is earning zero profits this is reminiscent of Ramsey pricing and the corresponding welfare is denoted by $S(R)$. If $\hat{x}_{f}<x_{f}, S\left(x_{f}\right)=u\left(x_{f}\right)-p\left(x_{f}\right) x_{f}$. Let $S(A)$ be the welfare at autarky, $x_{f 0}$ the minimum output for which $S(A)=S\left(x_{f}\right)$, $x_{f} \neq 0$ and $x_{f 1}$ the maximum output for which $S(R)=S\left(x_{f}\right)\left(x_{f 0}\right.$ and $x_{f 1}$ might be $\infty$ ) (see Figs. 1,2).

Proposition 3. If A.1 a) and A.2 hold, A.1 b) holds for positive outputs and $\beta(x)$ is non increasing in $x$, the optimal quota exists and is characterized by 


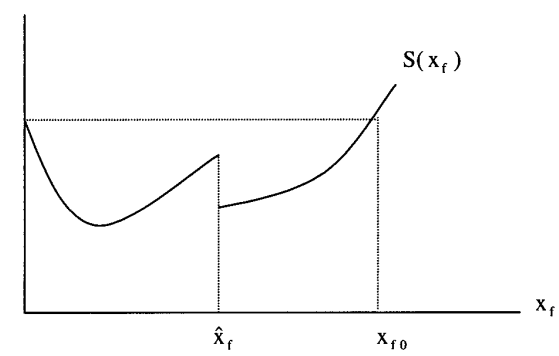

Fig. 1. Domestic welfare as a function of imports if $S\left(\hat{x}_{f}\right)<S(0)$

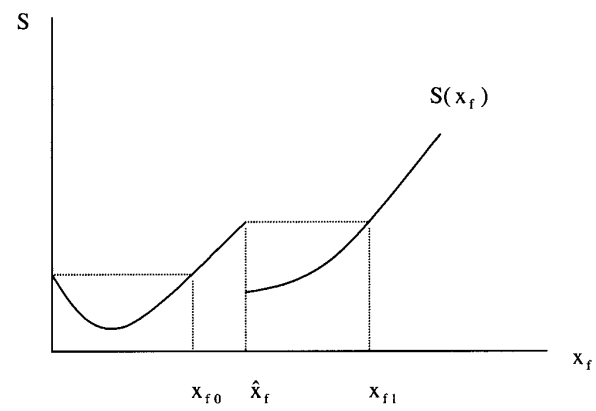

Fig. 2. Domestic welfare as a function of imports if $S\left(\hat{x}_{f}\right)>S(0)$

(a) If $S(A)>S(R)$ we have two possible cases
(a.i) $x_{f}=0$
if $\bar{x}_{f} \leq x_{f 0}$
(a.ii) $x_{f}=\bar{x}_{f}$
if $\bar{x}_{f} \geq x_{f 0}$

(b) if $S(A)<S(R)$ we have four possible cases
(b.i) $x_{f}=0 \quad$ if $\bar{x}_{f} \leq x_{f 0}$
(b.ii) $x_{f}=\bar{x}_{f} \quad$ if $\bar{x}_{f 0} \leq \bar{x}_{f} \leq \hat{x}_{f}$
(b.iii) $x_{f}=\hat{x}_{f} \quad$ if $\hat{x}_{f} \leq \bar{x}_{f} \leq x_{f 1}$
(b.iv) $x_{f}=\bar{x}_{f} \quad$ if $\bar{x}_{f} \geq x_{f 1}$

The case in which $S(A)>S(R)$ works like the non-fixed cost case: if the foreign firm has a relatively high marginal cost, total protection is the secondbest policy (case ai) and if the foreign firm has relatively low marginal cost, free trade is the second-best policy (case aii). In other words, the choices are total protection or free trade and the desirability of them depends on the relative efficiency of the foreign competitor.

However the case in which $S(A)<S(R)$ contains new features: A positive quota less than the Cournot equilibrium output of the foreign firm might be optimal and the desirability of free trade as second-best policy is not always related to the relative efficiency of the foreign firm: for high values of the marginal cost of the foreign firm total protection is second-best (case bi in Proposition 3), for high-intermediate values of the marginal cost free trade is second-best (case bii), for low-intermediate values of the marginal cost a quota of $\hat{x}_{f}$ is second-best 
(case biii) and for low values free trade is second-best again (case biv). In other words, $S(\mathrm{)})$ is no longer quasiconvex and the second-best policy is difficult to characterize. The bottom line is now "do not protect the very inefficient, protect the very efficient and be careful with the intermediate cases!" (see Figs. 1 and 2). ${ }^{4}$

Let us turn our attention to tariffs. To simplify the analysis, we assume that $\underline{t}<\bar{t}$ and that $S(t)<S(A)$ if $t<\underline{t}$ (i.e. domestic monopoly gives more welfare than foreign monopoly: this is true under linear demand). Let $t^{* *}$ be the secondbest tariff in the fixed cost model (recall that $t^{*}$ is the second-best tariff in the non fixed cost case).

Proposition 4. Let us assume that the cost function of the foreign firm is $C\left(x_{f}\right)=F+c x_{f}$ if $x_{f}>0$ and $C(0)=0$. If A.1 a) and A.2 hold, A.1 b) holds for positive outputs, and $\beta(x)$ is non decreasing in $x$, the optimal tariff exists and is characterized by

a) $t^{* *}>\bar{t}$ if $\underline{t}<\bar{t}<t^{*}$ and $S(\bar{t})<S(A)$ (see Fig. 3);

b) $t^{* *}=\bar{t}$ if $\underline{t}<\bar{t}<t^{*}$ and $S(\bar{t})>S(A)$ (see Fig. 4);

c) $t^{* *}=t^{*}$ if $\underline{t}<t^{*} \leq \bar{t}$ (see Fig. 5).

d) $t^{* *}=\underline{t}$ if $t^{*} \leq \underline{t}<\bar{t}$ (see Fig. 6).

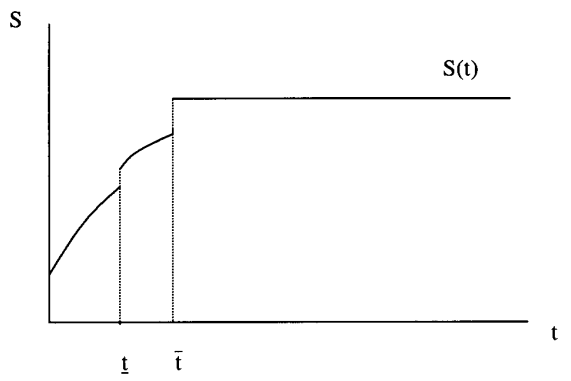

Fig. 3. Optimal tariff is $t^{* *}>\bar{t}$

According to Proposition 4, the second-best tariff depends on the efficiency of both firms, measured by their fixed costs. If the domestic firm is efficient we have three possible cases: A prohibitive tariff for high $F$ (case (a)), Ramsey pricing for the foreign firm for intermediate levels of $F$ (case (b)) and an interior tariff if $F$ is small (case (c)). If the domestic firm is inefficient then the second-best policy is Ramsey pricing for the domestic firm (case (d)).

Contrary to the continuous case, the second-best tariff might be not interior. Dixit (1984, 1988) and Venables (1986), also obtained boundary solutions for the case of no fixed costs but cost differences between domestic and foreign firms. However in those models the prohibitive tariff is the only non-interior solution, while our model offers additional possibilities (cases b and d). It is

\footnotetext{
${ }^{4}$ With respect to the likelihood of cases a) or b) it can be shown that if the inverse demand function is linear, $S(A)>S(R)$ iff $K$ is relatively high
} 


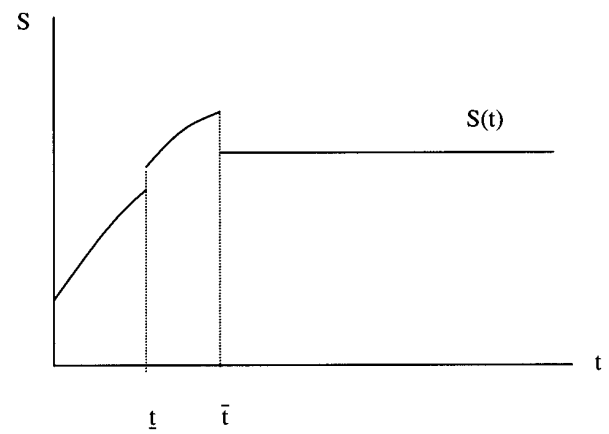

Fig. 4. Optimal tariff is $t^{* *}=\bar{t}$

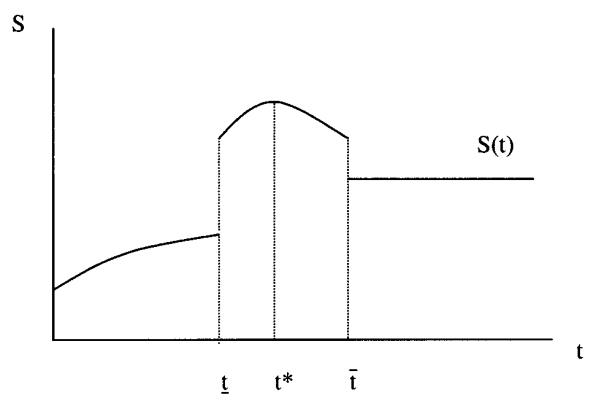

Fig. 5. Optimal tariff is $t^{* *}=t^{*}$

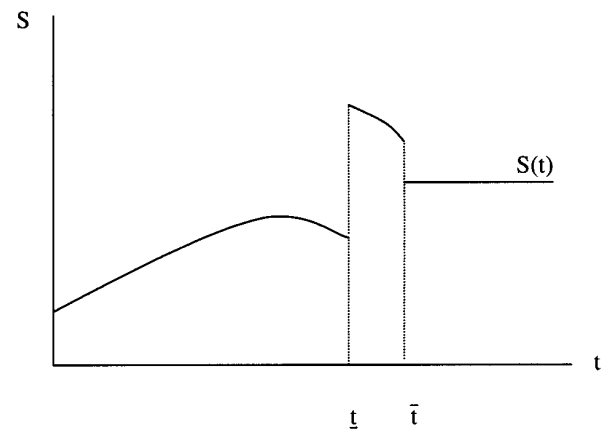

Fig. 6. Optimal tariff is $t^{* *}=\underline{t}$ 
interesting to note that the intuition behind this two cases is very different from the traditional protectionist arguments. The conventional intuition supporting a protectionist tariff is that it helps the strategic position of domestic firms, thereby increasing domestic profits, although consumers are worse-off. However, in case (d) domestic profits are zero. Thus a protectionist tariff is not used here to increase domestic profits but to increase domestic consumption and consumers' surplus.

\section{Final comments}

In this paper we have studied the second-best import policy in an oligopolistic market. Under zero fixed costs, if the policy instrument is a quota, the secondbest policy is either free trade or autarky, while if the instrument is a tariff the second-best policy is an interior solution. Contrary to previous contributions, we identify general conditions under which those results hold. Under positive fixed costs, we show that contrary to the traditional protectionist argument, a restrictive import policy might increase domestic welfare by increasing consumers surplus, not domestic profits.

In order to make our point we have chosen a particularly simple model. Thus, important topics like product differentiation, interaction of domestic and foreign markets, price-setting firms, dynamic issues, free entry, and subsidies to domestic firms are not covered by our model. We hope that our paper will stimulate similar research to ours on these areas.

\section{Appendix}

\section{Proof of Proposition 1.}

Part (i): Using (1), it is easy to compute

$$
\begin{aligned}
\frac{d S}{d x_{f}} & =u^{\prime}\left(\frac{d x_{d}}{d x_{f}}+1\right)-p^{\prime}\left(\frac{d x_{d}}{d x_{f}}+1\right) x_{f}-p-\sum_{i=1}^{n} c_{i}^{\prime} \frac{d x_{i}}{d x_{f}} \\
& =u^{\prime} \frac{d x_{d}}{d x_{f}}-p^{\prime} x_{f}\left(\frac{d x_{d}}{d x_{f}}+1\right)-\sum_{i=1}^{n} c_{i}^{\prime} \frac{d x_{i}}{d x_{f}} .
\end{aligned}
$$

Since for all firms for which the first order condition is fulfilled with inequality $d x_{i} / d x_{f}=0$, using (2) we get that

$$
\begin{aligned}
\frac{d S}{d x_{f}} & =u^{\prime} \frac{d x_{d}}{d x_{f}}-p^{\prime} x_{f}\left(\frac{d x_{d}}{d x_{f}}+1\right)-\sum_{i=1}^{n}\left(p+x_{i} p^{\prime}\right) \frac{d x_{i}}{d x_{f}} \\
& =-p^{\prime} x_{f}\left(\frac{d x_{d}}{d x_{f}}+1\right)-p^{\prime} \sum_{i=1}^{n} x_{i} \frac{d x_{i}}{d x_{f}}
\end{aligned}
$$

Next, we will show that A.1 implies that $\frac{d x_{d}}{d x_{f}}>-1$ and that $\frac{d x_{i}}{d x_{f}}<0, i=$ $1, \ldots, n$ (for the case of identical firms see Buffie and Spiller 1986, p. 68). First, 
first order conditions of profit maximization imply that if $x_{f}$ increases, neither $x$ nor $x_{i}, i=1, \ldots, n$ can be constant. Then, for a particular firm, say $i$, we have four possible cases.

$$
\begin{aligned}
& x \text { increases and } x_{i} \text { increases } \\
& x \text { increases and } x_{i} \text { decreases } \\
& x \text { decreases and } x_{i} \text { increases } \\
& x \text { decreases and } x_{i} \text { decreases }
\end{aligned}
$$

It is easy to see that Assumption 1 implies that cases (a) and (d) above are impossible. Suppose that (c) is true. Then it must be that case (c) holds for every $i=1, \ldots, n$. But since $x=x_{f}+x_{d}$ this is impossible, so case (b) holds for all firms and therefore $\frac{d x_{d}}{d x_{f}}>-1$ and $\frac{d x_{i}}{d x_{f}}<0, i=1, \ldots, n$. Thus, this part follows from these inequalities and equation (3) above.

Part (ii): Let $q \equiv x_{f} / x_{d}$. Then

$$
\begin{gathered}
\frac{d S}{d x_{f}}=-p^{\prime} x_{d}\left(q\left(\frac{d x_{d}}{d x_{f}}+1\right)+\frac{d x_{1}}{d x_{f}}\right) \\
\frac{d x_{i}}{d x_{f}}=-\frac{p^{\prime}+x_{i} p^{\prime \prime}}{n\left(p^{\prime}+x_{i} p^{\prime \prime}\right)+p^{\prime}}=-\frac{n(q+t)+\beta}{(n+1)(q+1) n+n \beta} .
\end{gathered}
$$

Thus

$$
\frac{d S}{d x_{f}}=-p^{\prime} x_{d} \frac{q^{2}-1-\beta / n}{(n+1)(q+1)+\beta} .
$$

By A.1 $\beta>-n(q+1)$ and thus $(n+1)(q+1)+\beta>0$. Disregarding the case in which $x_{d}=0$ (in which we know that $\frac{d S}{d x_{f}}>0$ ), $\frac{d S}{d x_{f}}=0$ iff $q=\sqrt{((1+\beta / n)}$ $\left(q>0\right.$ by A.1). The last equation implies that the $x_{f}$ for which $\frac{d S}{d x_{f}}=0$, denoted by $x_{f}^{\prime}$, is unique since $q$ is increasing on $x_{f}$ and $\beta$ is non increasing on $x$ (which in turn is increasing with $x_{f}$ ). Finally if $x_{f}>x_{f}^{\prime}, q$ increases and $\beta$ decreases so $\frac{d S}{d x_{f}}>0$ and if $x_{f}<x_{f}^{\prime}$, by identical reasoning $\frac{d S}{d x_{f}}<0$.

Part (iii): It is easily calculated that

$$
\operatorname{Sign}\left(\frac{d S}{d x_{f}}\left(\bar{x}_{f}\right)\right)=-\operatorname{Sign}\left(\frac{n\left(p^{\prime}+x_{i} p^{\prime \prime}\right)-p^{\prime}+c_{i}^{\prime \prime}}{n\left(p^{\prime}+x_{i} p^{\prime \prime}+p-c_{i}^{\prime \prime}\right.}\right) .
$$

Under constant returns the previous expression simplifies to

$$
\operatorname{Sign}\left(\frac{d S}{d x_{f}}\left(\bar{x}_{f}\right)\right)=-\operatorname{Sign} \frac{n \beta+n^{2}-1}{n \beta+(n+1)^{2}}
$$

where the denominator is positive (by A.1). Thus if $n=1$

$$
\operatorname{Sign}\left(\frac{d S}{d x_{f}}\left(\bar{x}_{f}\right)\right)=-\operatorname{Sign} \beta .
$$

If $n>1$, A.1 implies that the numerator of (4) is positive, so part (iii) is proved. 
Proof of Lemma 1. To show existence, let $z$ be such that $p(z)=c$. Now choose $\underline{t}$ such that the first order condition of profit maximization for the domestic firm is satisfied when this firm produces $z$ and $z=x(t)$.

Let $x^{*}$ be the aggregate output corresponding to a Cournot equilibrium where the foreign firm is inactive. Under A.1, $x^{*}$ exists. Let $\bar{t}=p\left(x^{*}\right)-c$. Facing a tariff $\bar{t}$ the foreign firm will choose zero output.

Let us now prove part (ii) of the lemma by calculating $\frac{d x}{d t}$ and $\frac{d x_{f}}{d t}$ from the first order conditions of profit maximization of every firm, i.e.

$$
\begin{gathered}
p+x_{i} p^{\prime}-c=0, \quad i=1, \ldots, n \quad \text { and } \\
p+x_{f} p^{\prime}-c-t=0 .
\end{gathered}
$$

Differentiating, we obtain that

$$
\begin{aligned}
\frac{d x_{f}}{d t} & =\frac{p^{\prime}+p^{\prime} / n+p^{\prime \prime} x_{i}}{p^{\prime}\left[p^{\prime}(1+2 / n)+p^{\prime \prime}\left(x_{i}+x_{f} / n\right)\right]}, \\
\frac{d x}{d t} & =\frac{1}{n\left[p^{\prime}(1+2 / n)+p^{\prime \prime}\left(x_{i}+x_{f} / n\right)\right]} .
\end{aligned}
$$

Now, we can calculate

$$
\begin{aligned}
n \cdot \frac{d x_{i}}{d t} & =\frac{d x}{d t}-\frac{d x_{f}}{d t} \\
& =-\frac{p^{\prime}+p^{\prime \prime} x_{i}}{p^{\prime}\left[p^{\prime}(1+2 / n)+p^{\prime \prime}\left(x_{i}+x_{f} / n\right)\right]} .
\end{aligned}
$$

But, according to our assumptions, (6), (7) are negative and (8) is positive, which completes the proof. Moreover, since $x_{i}(t)$ is strictly increasing and $x_{f}(t)$ is strictly decreasing, $\bar{t}$ and $\underline{t}$ are unique.

Proof of Proposition 2.

Part (i): Let

$$
\frac{d S}{d t}=p \cdot \frac{d x}{d t}-p \cdot \frac{d x_{f}}{d t}-x_{f} p^{\prime} \cdot \frac{d x}{d t}-c \frac{d x_{d}}{d t}+t \frac{d x_{f}}{d t}+x_{f}
$$

or

$$
\frac{d S}{d t}=\frac{d x}{d t} \cdot\left[p-x_{f} p^{\prime}-c\right]+\frac{d x_{f}}{d t} \cdot[t+c-p]+x_{f} .
$$

At the Cournot equilibrium $p-c+p^{\prime} x_{i}=p-c-t+p^{\prime} x_{f}=0$, so that

$$
\frac{d S}{d t}=\frac{d x}{d t}\left[t-2 x_{f} p^{\prime}\right]+\frac{d x_{f}}{d t} p^{\prime} x_{f}+x_{f} .
$$

If $t=\bar{t}>0$ then $x_{f}=0$ and the above derivative is negative in view of Lemma 1. If $x_{i}=0$ then $p=c$ and $t=p^{\prime} x_{f}$ so that $\frac{d S}{d t}=-p^{\prime} x_{f}\left(\frac{d x}{d t}-\frac{d x_{f}}{d t}\right)+x_{f}$, which is positive in view of Lemma 1.

Part (ii): Case $n=0$ : Expression (9) becomes 


$$
\frac{d S}{d t}=\frac{d x}{d t}\left(t-p^{\prime} x\right)+x
$$

From the first order condition of profit-maximization, it follows that

$$
\frac{d x}{d t}=\frac{1}{p^{\prime}(\beta+2)}
$$

which, substituted in our previous expression of $\frac{d S}{d t}$, gives

$$
\frac{d S}{d t}=\frac{1}{p^{\prime}(\beta+2)}\left[t+x p^{\prime}(\beta+1)\right],
$$

which is positive, under A. 1 , if $t<0$. Also, when $t$ is such that $x$ is near enough to zero, then $\frac{d S}{d t}$ is negative. Finally, domestic welfare is zero when $x=0$. Thus, $S(t)$ can be redefined on a compact interval and the proof of existence is completed, since $S(t)$ is a continuous function of $t$.

First order condition of welfare-maximization implies $\frac{d S}{d t}=0$ so that the optimal tariff must satisfy $t^{*}=-x p^{\prime}(\beta+1)$, which is positive under A.1. Now, we will show that if $\beta^{\prime}(x) \geq 0$, then $F(t) \equiv-\left[t+x p^{\prime}(\beta+1)\right]$ is strictly decreasing which implies that $S(t)$ is strictly quasi-concave, since $F(t)$ has the same sign as $\frac{d S}{d t}$ and both equal to zero just once. Thus, we compute

$$
\frac{d F}{d t}=-\left[1+x p^{\prime} \frac{d \beta}{d t}+(\beta+2)\left(p^{\prime}+x p^{\prime \prime}\right) \frac{d x}{d t}\right] \text {. }
$$

But, according to our assumptions, $\frac{d \beta}{d t}=\beta^{\prime} \frac{d x}{d t} \leq 0$, since $\frac{d x}{d t}<0$. Thus, by A.1 the above derivative must be negative. Therefore, $S(t)$ is strictly quasiconcave and the optimal tariff is unique.

Case $n \geq 1$ : Since $p(x(\underline{t}))-c=0$, from the first order conditions of profit maximization of the foreign firm we obtain that $\underline{t}=x_{f} p^{\prime}$. Thus, $\underline{t}$ is negative. Thus, according to the proof of existence in the case $n=0, S(t)$ must be strictly increasing for $t \leq \underline{t}$. On the other hand, Part (i) of this proposition implies that there exists some $t<\bar{t}$ yielding higher welfare than any $t \geq \bar{t}$. Therefore, no tariff outside the interval $[\bar{t}, \underline{t}]$ can yield larger social welfare. Thus the Weirstrass theorem and the continuity of $S(t)$ ensures the existence.

Since $t^{*}$ belongs to $[\bar{t}, \underline{t}]$, from Lemma 1(ii) it follows that $\underline{t}<t^{*}<\bar{t}$. Therefore, expression (9) is the relevant derivative of $S(t)$ in order to obtain $t^{*}$. By substituting (6) and (8) into (9) we obtain

$$
\begin{aligned}
\frac{d S}{d t} & =\frac{1}{n A}\left[t-2 p^{\prime} x_{f}+\left(p^{\prime}+p^{\prime} / n+p^{\prime \prime} x_{i}\right) n x_{f}+n A x_{f}\right] \\
& =\frac{1}{n A}\left[t+2 n\left(p^{\prime}+p^{\prime \prime} x_{i}\right) x_{f}+\left(p^{\prime}+p^{\prime \prime} x_{f}\right) x_{f}\right]
\end{aligned}
$$

where $A \equiv p^{\prime}(1+2 / n)+p^{\prime \prime}\left(x_{i}+x_{f} / n\right)<0$ (from A.1).

From the first order condition of welfare-maximization, the above derivative is equal to zero, which under our assumptions yields a positive $t^{*}$. 
Now, it remains to show that if $\beta^{\prime}(x) \geq 0$, then $S(t)$ is single picked, which ensures that $t^{*}$ is unique. From the first order condition of a Cournot equilibrium, it follows that $t=p^{\prime}\left(x_{f}-x_{i}\right)$. Thus, by using the definitions of $\beta(x)$ and $q \equiv x_{d} / x$, we can rewrite (11) as

$$
\begin{aligned}
\frac{d S}{d t} & =\frac{p^{\prime} x}{n A}\left\{2(n+1)(1-q)+\beta(1-q)^{2}-q / n\right\} \\
& =\frac{p x}{n A}\left(1-q^{2}\right)\left\{2(n+1) /(1+q)-q /\left[n\left(1-q^{2}\right)\right]+\beta\right\} .
\end{aligned}
$$

But $\operatorname{sign}\left\{\frac{d S(t)}{d t}\right\}$ is the same as the sign of $H(t)$ where this is defined as

$$
H(t) \equiv 2(n+1) /(1+q)-q /\left[n\left(1-q^{2}\right)\right]+\beta .
$$

By Lemma $1 x$ and $q$ are strictly decreasing in $t$, while $\beta$ is non decreasing in $x$. Therefore, $H(t)$ is strictly decreasing in $t$ and $S(t)$ is quasiconcave, so that $t^{*}$ is unique.

Proof of Proposition 3. Existence of the optimal quota follows from the closed graph of $S()$ and $x_{f} \in\left[o, \bar{x}_{f}\right]$. The characterization follows from the fact that Proposition 2 implies that $S($.$) is quasi-convex on \left[0, \hat{x}_{f}\right]$, and $S($.$) is strictly$ increasing on $\left(\hat{x}_{f}, \infty\right)$ (since $\left.\frac{\partial S}{\partial x_{f}}=u^{\prime}-p-p^{\prime} x_{f}=-p^{\prime} x_{f}>0\right)$ (see Figs. 1 and 2).

Proof of Proposition 4. Cases a) and b) follow from $S(t)<S(A)$ for $t<\underline{t}$ and by noticing that $S(t)$ is strictly increasing in $[\underline{t}, \bar{t}]$, due to Proposition 2(ii) (see Figs. 3 and 4). Case c) is obtained by using a similar argument as in Proposition 2(ii) and noticing that $S(A)<S(\bar{t})<S\left(t^{*}\right)$ (see Fig. 5). Case d) follows from $S(A)<S(\bar{t})$ and he fact that $S(t)$ is decreasing in $[\underline{t}, \bar{t}]$ (see Fig. 6).

\section{References}

Barros, P , Cabral, L (1992) Foreign Entry and Domestic Welfare, with an Application to Portuguese Life-Insurance In: Amaral, Lucena and Mello (eds ) The Portuguese Economy Towards 1992. Kluwer, Boston

Brander, J, Spencer, B (1984) Tariff Protection and Imperfect Competition In: Kierzkowski, H (eds ) Monopolistic Competition and International Trade Oxford University Press, Oxford

Buffie, E F , Spiller, P T (1985) Trade Liberalization in Oligopolistic Industries Journal of International Economics 20: 65-81

Collie, D R (1991) Export Subsidies and Countervaling Duties Journal of International Economics 31: 309-324

Collie, D R (1992) International Trade and Cournot Equilibrium: Existence, Uniqueness and Comparative Statics Bulletin of Economic Research 44: 55-56

Collie, D R (1993) Endogenous Timing in Trade Policy Games: Should Governments use Countervailing Duties? Mimeo, University of Warwick

Dixit, A (1984) International Trade Policy for Oligopolistic Industries Economic Journal 94: 1-16

Dixit, A (1988) Antidumping and Countervaling Duties under Oligopoly European Economic Review 32: 55-68

Dixit, A, Kyle, A (1985) The Use of Protection and Subsidies for Entry Promotion and Deterrence American Economic Review 75: 139-152

Eaton, J, Grossman, G (1986) Optimal Trade and Industrial Policy under Oligopoly Quarterly Journal of Economics 101: 383-406 
Eldor, R., Levin, D. (1990) Trade Liberalization and Domestic Monopoly: a Welfare Analysis. International Economic Review 31: 773-782

Friedman, J. (1982) Oligopoly Theory. In: Arrow, K., Intrilligator, M. (eds.) Handbook of Mathematical Economics. North Holland, Amsterdam

González-Maestre, M. (1993) R\&D, Trade Policy and the Paradox of Autarky. Revista Española de Economía. Monogràfico: "Investigación y Desarrollo": 151-164

Helpman, E. (1981) International Trade in the Presence of Product Differentiation, Economies of Scale and Monopolistic Competition. A Chamberlin - Hecksher-Olin Approach. Journal of International Economics 11: 305-340

Helpman, E. (1984) Increasing Returns, Imperfect Markets and Trade Theory. In: Jones, R.W., Kenan, P.B. (eds.) Handbook of International Economics . North Holland, Amsterdam

Helpman, E, Krugman, P.R. (1989) Trade Policy and Market Structure. MIT Press, Cambridge, MA

Horstman, I. J., Markusen, J.R. (1986) Up the Average Cost Curve: Inefficient Entry and the New Protectionism. Journal of International Economics 20: 225-248

Horstman, I. J., Markusen, J.R. (1992) Endogenous Market Structures in International Trade. Journal of International Economics 32: 109-129

Krishna, K., M. Thursby (1991) Optimal Policies with Strategic Distortions. Journal of International Economics 31: 291-308

Krugman, P.R. (1979) Increasing Returns, Monopolistic Competition and International Trade. Journal of International Economics 9: 469-479

Krugman, P.R. (1989) Industrial Organization and International Trade. In: Schmalensee, R., Willing, R. (eds.) Handbook of Industrial Organization . Vol. 2, Ch. 20. North Holland, Amsterdam

Laussel, D., Montet, C., Peguin-Feissolle, A. (1988) Optimal Trade Policy under Oligopoly. European Economic Review 32: 1547-1565

Markusen, J.R. and Venables, A.J. (1988) Trade Policy with Increasing Returns and Imperfect Competition. Journal of International Economics 24: 299-316

Motta, M. (1992) Multinational Firms and the Tariff-jumping Argument: A Game Theoretic Analysis with Some Unconventional Conclusions. European Economic Review 36: 1557-1571

Ono, Y. (1990) Foreign Penetration and National Welfare under Oligopoly. Japan and the World Economy 2: 141-154

Rowthorn, R.E. (1992) Intra-industry Trade and Investment under Oligopoly: The Role of Market Size. Economic Journal 102: 402-414

Venables, A.J. (1985) Trade and Trade Policy with Imperfect Competition: The Case of Identical Products and Free Entry. Journal of International Economics 19: 1-20

Venables, A.J. (1986) Production Subsidies, Import Tariffs and Imperfectly Competitive Trade. In: Greenaway, D., Tharakan, P. (eds.) Imperfect Competition and International Trade: The Policy Aspects of Intra-industry Trade. Wheatsheaf, Brighton 